Article publié par le Laboratoire de Construction en Béton de l'EPFL

\begin{tabular}{|l|l|}
\hline Title: & Study on Influence of Column Size and Slab Slenderness on Punching Strength \\
\hline Authors: & Einpaul J., Bujnak J., Fernández Ruiz M., Muttoni A. \\
\hline Published in: & ACI Structural Journal \\
\hline DOI & $10.14359 / 51687945$ \\
\hline $\begin{array}{l}\text { Volume: } \\
\text { Pages: }\end{array}$ & $\begin{array}{l}\text { V. } 113 \\
\text { pp. } 135-145\end{array}$ \\
\hline City, country: & Farmington Hills, USA \\
\hline Year of publication: & 2016 \\
\hline Type of publication: & Peer reviewed journal article \\
\hline
\end{tabular}

Please quote as:

Einpaul J., Bujnak J., Fernández Ruiz M., Muttoni A., Study on Influence of Column Size and Slab Slenderness on Punching Strength, ACI Structural Journal, V. 113, Farmington Hills, USA, 2016, pp. 135-145. 


\title{
Study on Influence of Column Size and Slab Slenderness on Punching Strength
}

\author{
by Jürgen Einpaul, Jan Bujnak, Miguel Fernández Ruiz, and Aurelio Muttoni
}

\begin{abstract}
This paper presents the results of a systematic experimental campaign consisting of 13 symmetric punching tests on interior slab-column connections. The study focuses on the influence of varying the size of the supported area and the slenderness of the slab. Other investigated parameters are the flexural reinforcement ratio and the presence of shear reinforcement. The results of the present campaign and of previous tests are compared to the predictions of different codes of practice and to the critical shear crack theory (CSCT). The comparison shows that the CSCT and fib Model Code 2010 give the most consistent predictions, whereas the results of Eurocode 2 for small support sizes have a large scatter. The predictions of ACI 318 are observed as overall conservative in the investigated range. This study shows that slenderness has an important influence on the punching strength of slabs with shear reinforcement, despite the fact that it is neglected in many codes of practice.
\end{abstract}

Keywords: code comparisons; critical shear crack theory (CSCT); experimental campaign; flat plates; punching shear; slenderness.

\section{INTRODUCTION}

Reinforced concrete slabs supported on columns are common in residential and commercial buildings. Slabs with large concentrated loads can also be found in other types of structures, such as cut-and-cover tunnels or slab bridges supported on columns. In many cases, these elements are only equipped with flexural reinforcement and no transverse reinforcement is provided. Punching shear is often the governing failure mode for such elements. Such failures are usually associated with very small deformations and crack widths prior to failure and, as such, can occur without noticeable warning signs. Furthermore, the mechanism of punching failure is still poorly understood. The punching provisions in codes of practice ${ }^{1-3}$ are based on different theories or on empirical formulas, thus in some cases leading to very different strength predictions.

Among the mechanical models for punching of slabcolumn connections, the critical shear crack theory (CSCT) developed by Muttoni ${ }^{4}$ has shown wide consistency and generality, serving as a basis ${ }^{5}$ of the punching provisions of Model Code 2010. ${ }^{3}$ Similar to the first mechanical model of Kinnunen and Nylander, ${ }^{6}$ it assumes that the punching shear strength of a slab is a function of its flexural deformations (referring to a strain effect on punching shear). Larger flexural deformations (slab rotation $\psi$ ), such as in the case of lower amount of flexural reinforcement or more slender slabs (Fig. 1(a)), lead to wider cracks in the vicinity of the column and thus decrease the strength of a shear-carrying concrete strut, thereby lowering the punching capacity $\left(V_{R}\right)$. (a)
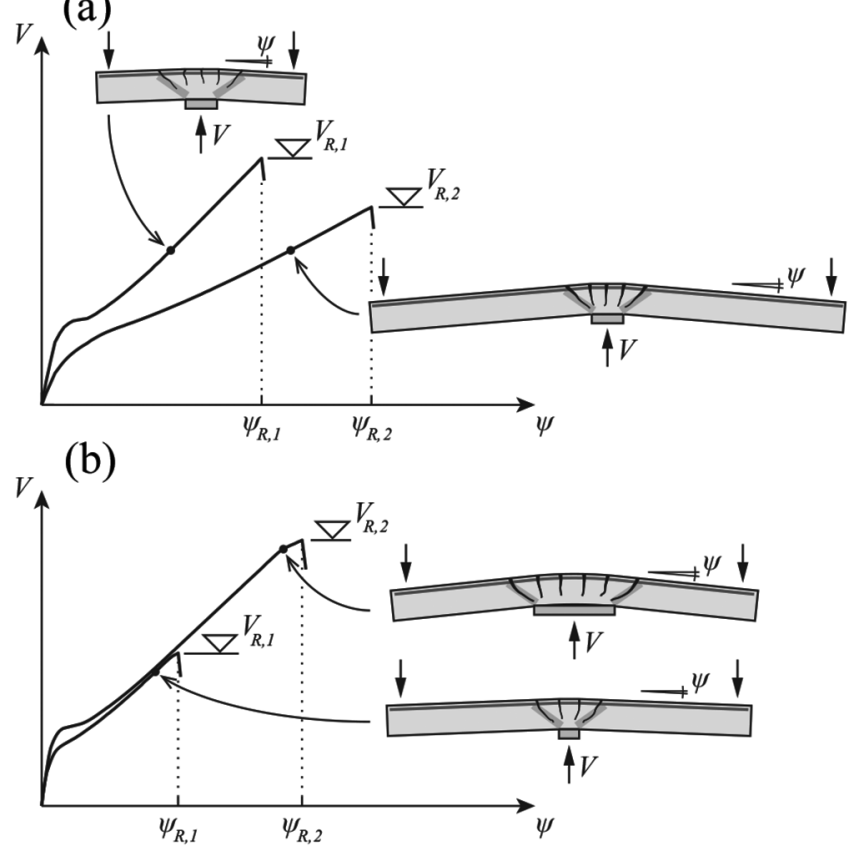

Fig. 1-Load-rotation response and punching strength of slab specimens: (a) influence of specimen slenderness; and (b) influence of column size.

Some empirical formulas, such as those of Eurocode $2^{2}$ punching provisions, account for the influence of the flexural reinforcement ratio. Yet, the effect of slab slenderness is neglected in Eurocode 2 as in most codes of practice. ${ }^{1,2}$

The mechanical model of the CSCT also provides a physical explanation for the effect observed by Vanderbilt ${ }^{7}$ that increasing column size decreases the nominal punching shear strength per unit length of a control perimeter close to the column face. This is explained by the fact that when the length of the shear-critical perimeter increases, punching failures occur at higher loads. However, increasing the column size has only a limited influence on the load-rotation response of a slab (Fig. 1(b)). Therefore, higher loads lead to increased rotations and larger crack widths in the critical zone of the slab around the column that decrease the capacity of concrete to transfer shear stresses between the slab and the column. This is, again, related to a strain effect. As a conse-

ACI Structural Journal, V. 113, No. 1, January-February 2016

MS No. S-2015-069, doi: 10.14359/51687945, received March 9, 2015, and reviewed under Institute publication policies. Copyright (C) 2016, American Concrete Institute. All rights reserved, including the making of copies unless permission is obtained from the copyright proprietors. Pertinent discussion including author's closure, if any, will be published ten months from this journal's date if the discussion is received within four months of the paper's print publication. 
(a)
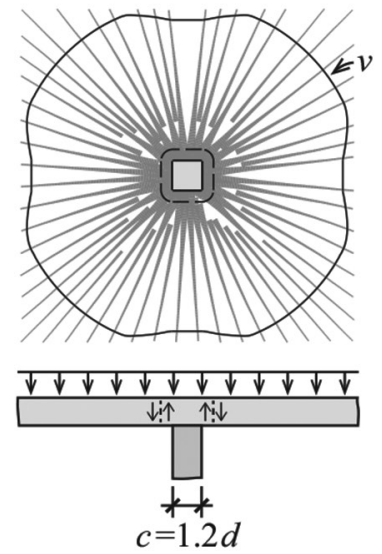

(b)

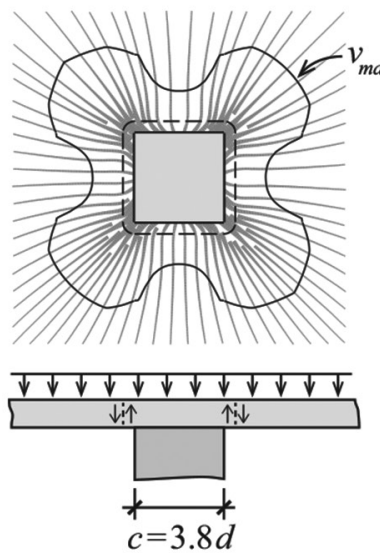

(c)

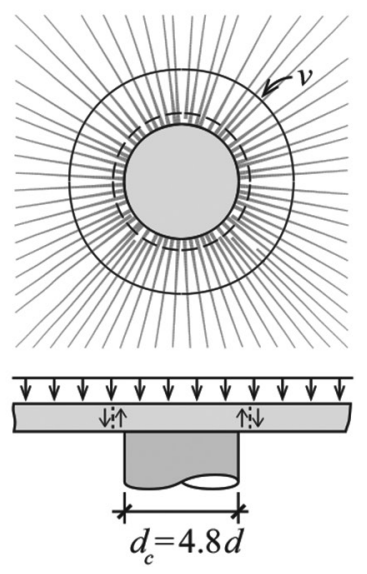

Fig. 2-Shear fields in vicinity of columns and distribution of shear stresses on control perimeter at $\mathrm{d} / 2$ from column edge: (a) small square column; (b) large square column; and (c) large round column.

quence, the CSCT predicts that the unitary punching shear strength on a control perimeter of a slab-column connection decreases with increasing column size in agreement to the observations of Vanderbilt. ${ }^{7}$

Another effect that may reduce the punching capacity of large square or rectangular columns is related to possible stress concentrations in the column corners. ${ }^{8}$ Figure 2 shows the shear fields ${ }^{9}$ and distribution of shear stresses (calculated assuming linear-elastic slab behavior) in a slab at a distance $d / 2$ from the column edge for different column sizes and shapes. Whereas the distribution can be assumed as uniform for small square columns (Fig. 2(a)) as well as for circular columns (Fig. 2(c)), higher stresses in column corners can be noted in the case of large square columns (Fig. 2(b)). To account for this effect, the CSCT recommends assuming that only the parts of the control perimeter that are close to the column corners (at distances smaller than $1.5 d$ ) are active in carrying shear stresses.

The predictions of CSCT for punching of slab-column connections with variable column sizes, related to the described phenomena, have been confirmed by previous test results $^{10}$ (refer to Fig. 3(a)). It should yet be noted that all these tests were performed using square columns. To avoid stress concentrations in the column corners, a new test series that is presented in the current paper is performed using round columns. A very wide range of column diameters is used ( 83 to $660 \mathrm{~mm}$ [3.3 to $26 \mathrm{in}$.]). Four of the slabs have a flexural reinforcement ratio of $0.75 \%$ and four slabs $1.50 \%$. All other parameters are kept constant.

As previously explained (Fig. 1(a)), slenderness of a specimen also has an influence on the punching strength. This is shown in Fig. 3(b) where available tests results are compared to the CSCT. Unfortunately, tests on specimens with constant thicknesses but varying slendernesses (defined as $B / 2 d$ ) are scarce in the scientific literature ${ }^{11}$ (Fig. 3(b)). To provide extended test data on this topic, a second test series is presented in the current paper where the size of the column and slab thickness are kept constant but the specimen slenderness ratio $B / 2 d$ is varied between 4.0 and 9.6. Three of the second-series slabs are also equipped with shear reinforce-

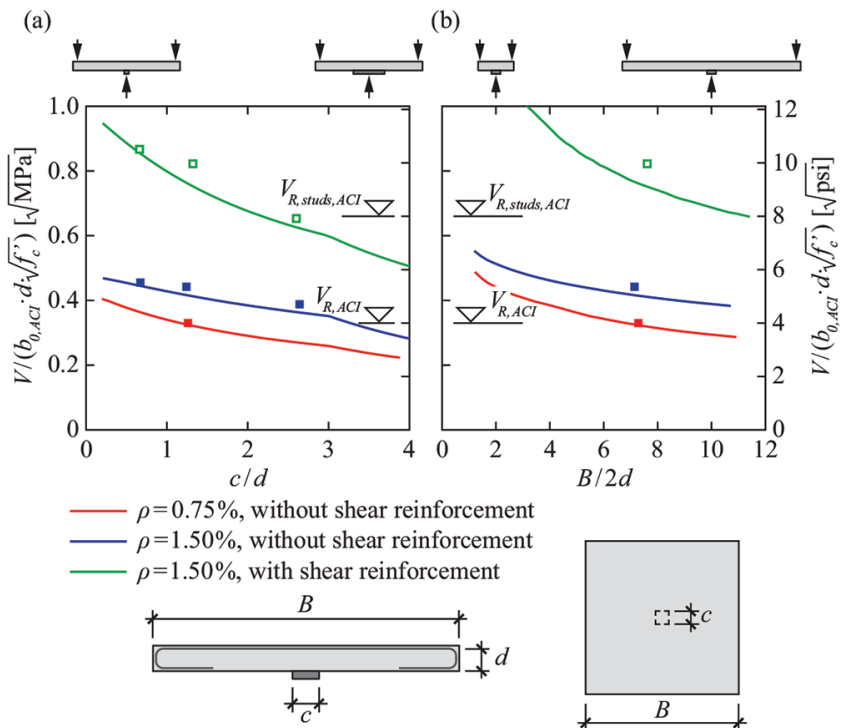

Fig. 3-Predicted punching strengths according to $\mathrm{CSCT}^{4}$ and results of previous tests ${ }^{10,24}$ : (a) influence of column size; and (b) influence of specimen size.

ment, cases where the predicted influence of slenderness is especially strong (refer to the top curve in Fig. 3(b)).

In this paper, all the experimental results as well as some previous results ${ }^{10-12}$ are compared to the predictions of the $\mathrm{CSCT}^{4}$ and some major codes of practice-ACI $318,{ }^{1}$ Eurocode $2,{ }^{2}$ and Model Code $2010^{3}$ - to discuss on their suitability and accuracy.

\section{RESEARCH SIGNIFICANCE}

The provisions of different codes of practice deal with punching failures in different manners, sometimes resulting in conflicting design outcomes. In addition, existing experimental research on the influence of column size and slab slenderness on shear strength of slab-column connections is limited. In the current paper, a systematic test campaign is presented addressing such cases. The test results show the significance of both parameters on the punching shear strength (related to strain effect). The results are used to 

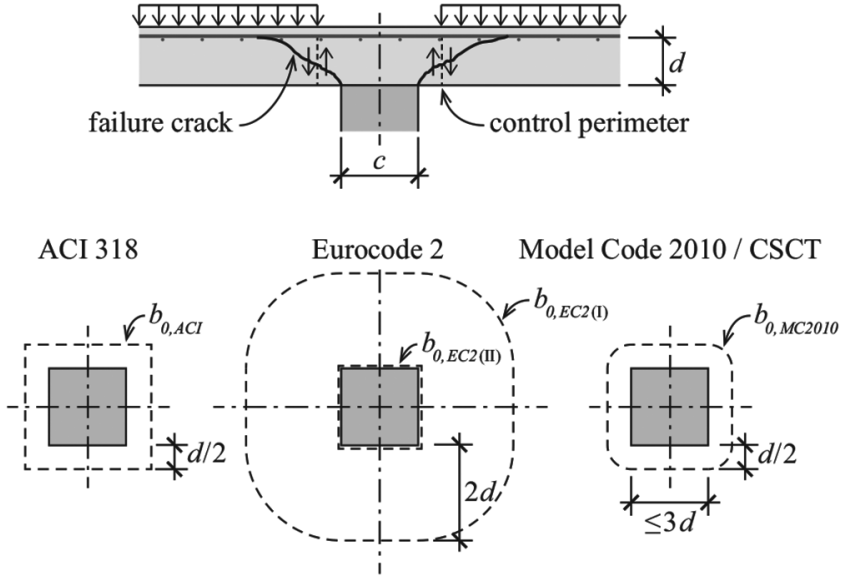

Fig. 4-Control perimeters for punching verification in codes of practice.

investigate the consistency of the mechanical model of CSCT as well as the accuracy of some empirical design formulas.

\section{PUNCHING PROVISIONS IN CODES OF PRACTICE}

In all major codes of practice, punching strength of flat plates is verified by comparing the nominal shear strength of an element to a nominal shear stress on a unit length of a control perimeter around a column or a loaded area (Fig. 4)

$$
v=\frac{V}{b_{0} \cdot d} \leq v_{R}
$$

The control perimeter $b_{0}$ should be defined in a manner that allows using nominal shear strengths that are independent of the column shape and size. It should be noted that, for this reason, the control perimeter and the actual failure surface are not directly related. Therefore, the definition of a control perimeter may be governed by very different rules depending on the code. ${ }^{1-3}$ Its location may vary between the edge of the loaded area and a distance $2 d$ from it, its corners may be rounded or sharp and the length may be reduced in the vicinity of openings, slab edges or in the case of long straight edges of the loaded area (Fig. 4).

\section{Influence of column size}

The different location of control perimeters in various codes affects the influence of the loaded area size on their punching shear strength predictions. In addition, the codes account for different parameters in their punching strength formulas. Figure 5 shows the resistance of a continuous slab to a concentrated load (as nominal shear strength on the ACI 318 control perimeter) as a function of the size of the loaded area with respect to the slab depth according to different codes of practice and for two different reinforcement ratios. The capacity of the slabs may be governed by punching shear or flexural failure. The flexural strengths are calculated using the yield line method with a fan-shaped mechanism (Fig. 6), where the location of the positive yield line is $r_{y l}$ that had to be optimized to obtain the minimal flexural strength. To that purpose, the amount of positive flexural reinforcement in the slab investigated in Fig. 5 is (a)

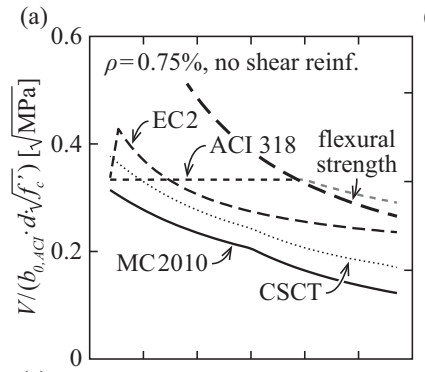

(b)

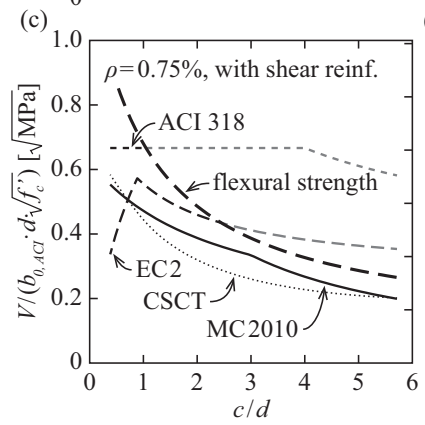

(d)
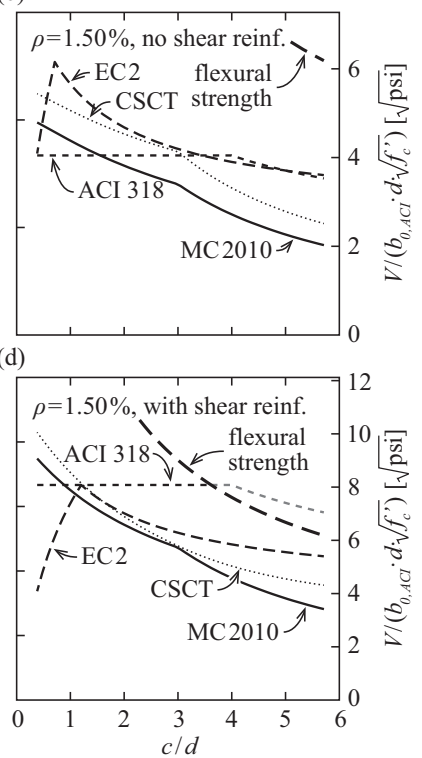

Fig. 5-Comparison of punching predictions of Eurocode 2, ACI 318, and Model Code 2010, without shear reinforcement and with large amounts of shear reinforcement (double-headed studs), depending on column size-slab depth ratio (for square columns): (a) slabs with $\rho=0.75 \%$ and no shear reinforcement; (b) slabs with $\rho=1.5 \%$ and no shear reinforcement; (c) slabs with $\rho=0.75 \%$ and double-headed shear studs; and (d) slabs with $\rho=1.5 \%$ and double-headed shear studs. (Parameters: $\mathrm{L}=7 \mathrm{~m}[22.9 \mathrm{ft}] ; \mathrm{d}=210 \mathrm{~mm}$ [8.27 in.]; $\mathrm{f}_{\mathrm{c}}=35 \mathrm{MPa}$ [5080 psi]; $\mathrm{f}_{\mathrm{y}}=420 \mathrm{MPa}$ [60.9 ksi]; $\rho=0.75 \%$ or $\rho=1.5 \% ; \mathrm{d}_{\mathrm{g}}=16 \mathrm{~mm}[0.63 \mathrm{in.}$. .)

assumed to be half the amount of negative reinforcement. It should be noted that, depending on the geometry of the slab, folding mechanisms may also be governing. In the case of using sufficiently large columns (relative to slab depth) and low reinforcement ratios or when using shear reinforcement, punching failure can be avoided and bending may limit the load-bearing capacity of the slab (with enhanced deformation capacity). However, in many cases, a brittle shear failure is predicted before the full development of yield lines.

Since 1963, the punching or two-way shear provisions of ACI $318^{1}$ are largely based on the work of Moe published in $1961 .{ }^{13}$ For cases in between one-way and two-way slab action, such as rectangular or very large loaded areas, modifications were made in 1977, where the predictions tend towards one-way shear strengths for elongated columns $\left(c_{1} / c_{2}>2\right)$ or large column size-slab depth ratios $(c / d>4) .{ }^{14}$ In comparison to the other codes, it can be seen that ACI 318 predicts significantly higher shear capacities for slabs with lower reinforcement ratios and medium $c / d$ (between 2 and 4) (Fig. 5(a)). In these cases (corresponding to typical floor slabs with low slenderness that do not require large quantities of flexural reinforcement), the column size does not lead to the reduction of nominal shear strength. Such reduction is based on the tests by Vanderbilt ${ }^{7}$ that were performed on very thin slabs $(h=51 \mathrm{~mm}[2 \mathrm{in}]$.$) . As the phenomenon$ of punching is known to exhibit significant size effect (a decrease in nominal shear strength for increasing slab thick- 


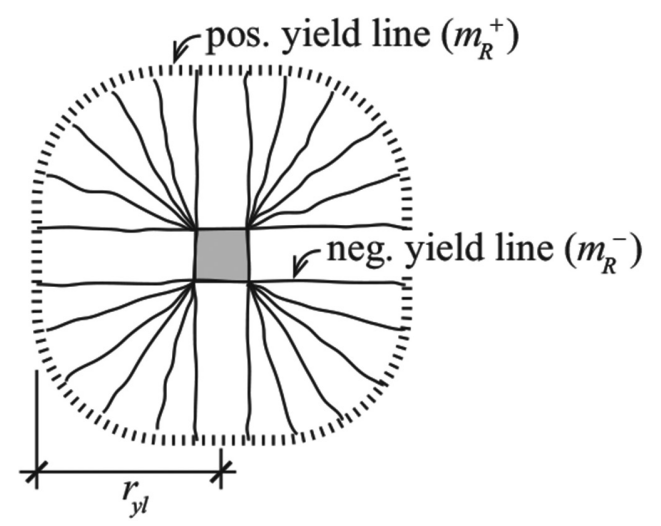

Fig. 6-Yield line pattern for flexural failure of continuous slab.

ness), these tests may have overestimated the punching strength of slabs on large supports (such as drop panels).

The punching provisions of Eurocode $2^{2}$ are based on Model Code $1990^{15}$ and due to the location of the control perimeter further than in ACI 318, exhibit less significant influence on column size to slab depth ratio. In 1986, Regan ${ }^{12}$ reported that the British standard of that time ${ }^{16}$ (that used a control perimeter at $1.5 d$ from the column edge) provided unsafe predictions in the case of very small $c / d$ ratios (less than 0.75 ) and recommended that additional verification on a smaller control perimeter be introduced. Similar verification was also added in Eurocode 2 that checks the shear stress at a control perimeter located at a column face with a higher nominal strength $\left(v_{R, \max }\right)$. This verification is governing in the case of very small values of $c / d$ can be seen in Fig. 5 as different regime in the Eurocode 2 predictions. This formula only considers the concrete strength and the slab depth as parameters and does not account for other influences, including the flexural reinforcement ratio. Therefore, the provisions of Eurocode 2 lead to more conservative results for slabs with large amounts of flexural reinforcement supported on small columns.

The punching provisions of Model Code $2010^{3}$ are based on the $\mathrm{CSCT}^{4}{ }^{4} \mathrm{~A}$ consistent approach for all column sizes is used. The CSCT directly accounts for the flexural deformations of the slab and allows accounting for the size and strain effects on its punching strength model. ${ }^{17}$ The control perimeter is located at $0.5 d$, similarly to ACI 318 , but the nominal shear strength is dependent on slab rotation $\psi$, decreasing for increasing column size. Therefore, the influence of column size is more similar to the predictions of Eurocode 2 than to ACI 318. Accounting for the influence of the flexural deformations, it allows thus a gradual reduction of the punching strength when flexural limit is approached, suitably describing the transition between shear and flexural failures in a physical manner.

Differences between the codes of practice are even more important in the case of slabs with shear reinforcement (Fig. 5(c) and (d)). Such slabs fail at higher load levels and at larger deformations than slabs without shear reinforcement. ${ }^{18}$ For low or moderate amounts of transverse reinforcement, increasing the shear reinforcement ratio also increases the punching capacity. However, tests ${ }^{10}$ have indicated that for very large amounts of shear reinforcement, concrete close to the edge of the loaded area is governing and may crush before the shear reinforcement yields. For such cases, the punching capacity is no longer increased for larger amounts of transverse reinforcement. ${ }^{18}$ In this failure mode, punching strength depends on the type of shear reinforcement and detailing rules (anchorage type, reinforcing bar spacing). Therefore, design codes define a limit on the maximum punching strength of shear-reinforced slabs. In ACI 318 and Model Code 2010, the limit depends on the shear reinforcement system with highest resistances for double-headed studs. In Eurocode 2, the maximum punching resistance of shear-reinforced slabs is limited by the same verification of $v_{R, \max }$ at the edge of the column as for slabs without shear reinforcement. This leads to lower predictions compared to the other codes for small column size to slab depth ratios (up to approximately 1), as according to this approach, using shear reinforcement does not increase the punching resistance. Predictions for larger column sizes, however, lead to higher strengths. Until recently, Eurocode 2 punching provisions did not include any other limitation on the punching strength of slabs with shear reinforcement. In 2014, an amendment ${ }^{19}$ to Eurocode 2 punching provisions was published (to be implemented by the end of 2015) so that the punching resistances of shear-reinforced slabs were limited to 1.5 times the resistances of similar slabs without shear reinforcement. That leads to similar predictions than of Model Code 2010. However, the limitation of $v_{R, \max }$ remained unchanged and thus the punching strength predictions of Eurocode 2 for the connections of slabs to columns having small sizes with respect to slab depth (that are common in European practice) are more conservative than the provisions of ACI 318 and Model Code 2010 (Fig. 5(c) and (d)).

\section{Influence of slab slenderness}

Punching tests are normally performed on isolated test specimens that represent a negative moment area of a continuous slab, separated from the rest of the slab by the line of moment contraflexure. In slender slabs with regular spans $L$, according to a linear-elastic calculation, the distance from the center of the column to this line is approximately $0.22 L^{6,20}$ (this has been observed in nonlinear analyses ${ }^{20}$ to be a reasonable approximation also for cracked continuous slabs). Therefore, the slenderness of a specimen $(B / 2 d)$ corresponds to 0.22 times the slenderness of an actual flat plate $(L / d)$. Experimental results have shown that increasing specimen slenderness reduces both its flexural stiffness and shear capacity. ${ }^{21}$ This suggests that punching shear strength of an actual slab decreases with increasing span if the depth of the member remains constant. It is thus instrumental to select the size of a specimen considering the slenderness of the actual slab that is modeled in the experiment. Despite this fact, in many experimental campaigns, the size of specimens is chosen only based on existing laboratory conditions.

The mechanical model of Kinnunen and Nylander ${ }^{6}$ as well as a design method based on their model from the Swedish concrete handbook of $1990^{22}$ account for the slenderness effect. Also the $\mathrm{CSCT}^{4}$ and the codes that base their punching provisions on this theory (Model Code $2010^{3}$ and, since 2003, the Swiss code for concrete construction ${ }^{23}$ ) 
Table 1-Main parameters of test specimens

\begin{tabular}{c|c|c|c|c|c|c|c|c}
\hline Slab & $B, \mathrm{~m}(\mathrm{ft})$ & $r_{q}, \mathrm{~m}(\mathrm{ft})$ & $c, \mathrm{~mm}(\mathrm{in})$. & $d_{c}, \mathrm{~mm}(\mathrm{in})$. & $d, \mathrm{~mm}(\mathrm{in})$. & $\rho, \%$ & $f_{y}, \mathrm{MPa}(\mathrm{ksi})$ & $f_{c}, \mathrm{MPa}(\mathrm{psi})$ \\
\hline PE10 & $3.0(9.84)$ & $1.505(4.94)$ & - & $83(3.27)$ & $210(8.27)$ & 0.77 & $538(78.0)$ & $40.4(5860)$ \\
\hline PE11 & $3.0(9.84)$ & $1.505(4.94)$ & - & $166(6.54)$ & $215(8.46)$ & 0.75 & $538(78.0)$ & $37.5(5440)$ \\
\hline PE9 & $3.0(9.84)$ & $1.505(4.94)$ & - & $330(13.0)$ & $218(8.52)$ & 0.74 & $538(78.0)$ & $44.1(6390)$ \\
\hline PE12 & $3.0(9.84)$ & $1.505(4.94)$ & - & $660(26.0)$ & $212(8.35)$ & 0.76 & $538(78.0)$ & $37.6(5450)$ \\
\hline PE6 & $3.0(9.84)$ & $1.505(4.94)$ & - & $83(3.27)$ & $215(8.46)$ & 1.46 & $542(78.6)$ & $38.4(5570)$ \\
\hline PE7 & $3.0(9.84)$ & $1.505(4.94)$ & - & $166(6.54)$ & $213(8.39)$ & 1.47 & $542(78.6)$ & $42.5(6160)$ \\
\hline PE8 & $3.0(9.84)$ & $1.505(4.94)$ & - & $330(13.0)$ & $214(8.43)$ & 1.47 & $542(78.6)$ & $42.0(6090)$ \\
\hline PE5 & $3.0(9.84)$ & $1.505(4.94)$ & - & $660(26.0)$ & $210(8.27)$ & 1.50 & $542(78.6)$ & $36.7(5320)$ \\
\hline PE4 & $1.7(5.58)$ & $0.765(2.51)$ & $260(10.2)$ & - & $197(7.76)$ & 1.59 & $517(75.0)$ & $35.1(5090)$ \\
\hline PV1 ${ }^{24}$ & $3.0(9.84)$ & $1.505(4.94)$ & $260(10.2)$ & - & $210(8.27)$ & 1.50 & $709(102.8)$ & $31.1(4510)$ \\
\hline PE3 & $3.9(12.8)$ & $1.926(6.32)$ & $260(10.2)$ & - & $204(8.03)$ & 1.54 & $517(75.0)$ & $34.2(4960)$ \\
\hline PP4 & $1.7(5.58)$ & $0.765(2.51)$ & $260(10.2)$ & - & $211(8.31)$ & 1.49 & $510(74.0)$ & $30.9(4480)$ \\
\hline PP5 & $2.3(7.55)$ & $1.120(3.67)$ & $260(10.2)$ & - & $205(8.07)$ & 1.53 & $510(74.0)$ & $31.5(4570)$ \\
\hline PL7 10 & $3.0(9.84)$ & $1.505(4.94)$ & $260(10.2)$ & - & $197(7.76)$ & 1.59 & $583(84.5)$ & $35.9(5210)$ \\
\hline PP6 & $3.9(12.8)$ & $1.926(6.32)$ & $260(10.2)$ & - & $203(7.99)$ & 1.55 & $510(74.0)$ & $32.7(4740)$ \\
\hline
\end{tabular}

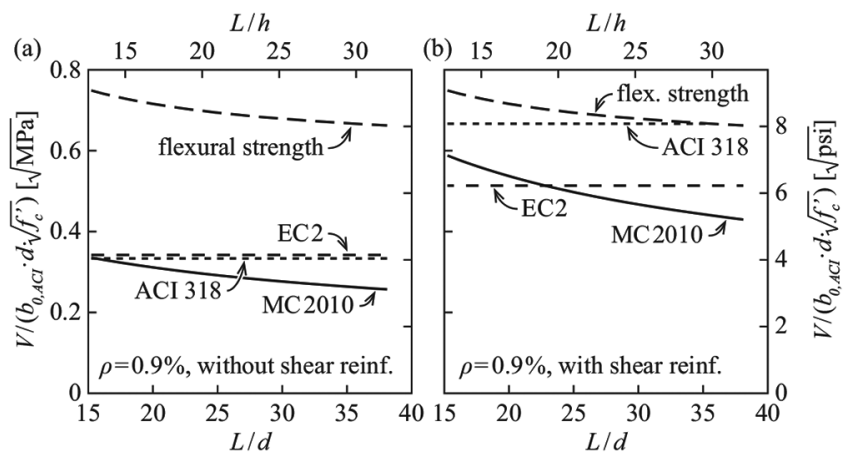

Fig. 7-Comparison of punching predictions of Eurocode 2, $A C I$ 318, and Model Code 2010, without shear reinforcement and with large amounts of shear reinforcement (doubleheaded studs), depending on slab slenderness: (a) slabs with $\rho=0.9 \%$ and no shear reinforcement; and (b) slabs with $\rho=$ $0.9 \%$ and double-headed shear studs. (Parameters: refer to Fig. 2; $\mathrm{c}=350 \mathrm{~mm}$ [13.8 in.].)

take this effect into account. However, slenderness is not accounted for as a parameter in the design equations of ACI $318^{1}$ and Eurocode $2^{2}$ (Fig. 7). It only affects the flexural strength of a slab, which may become the governing failure mode for more slender slabs with fairly low amounts of flexural reinforcement or for slabs with shear reinforcement. According to those codes, the shift from shear to flexural failure is considered without a transition phase. According to Model Code 2010, a pure flexural failure is predicted for much more slender slabs with a transition phase where the governing failure mode is still punching but with large flexural deformations due to yielding of flexural reinforcement in the column area. Increasing the slab slenderness has a similar influence as reducing the flexural reinforcement ratio, as the punching strength is based on the state of flexural deformations. This allows calculating the reduction of strength and deformation capacity close to the flexural limit in a more refined manner. (a)
Series I

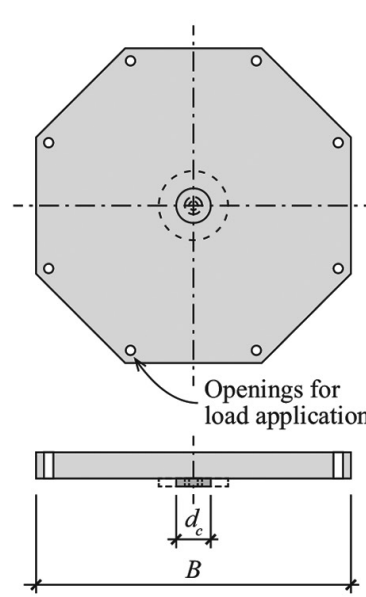

Series II

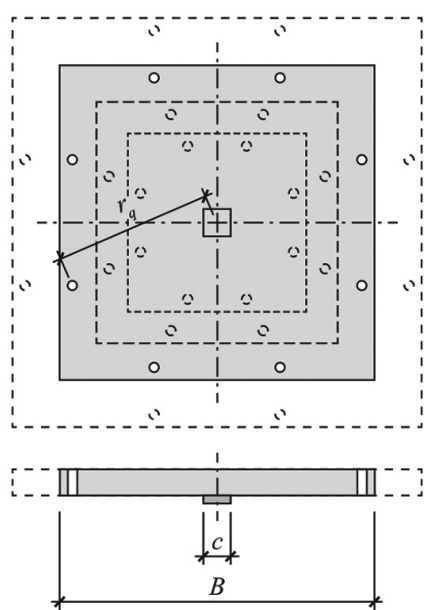

(b)
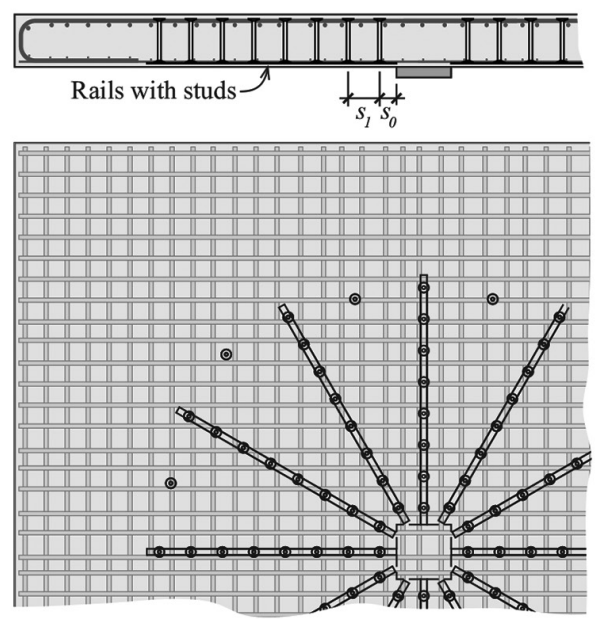

Fig. 8-Test specimens: (a) geometric parameters; and (b) placement of double-headed shear studs in Specimens PP4, PP5, and PP6. 


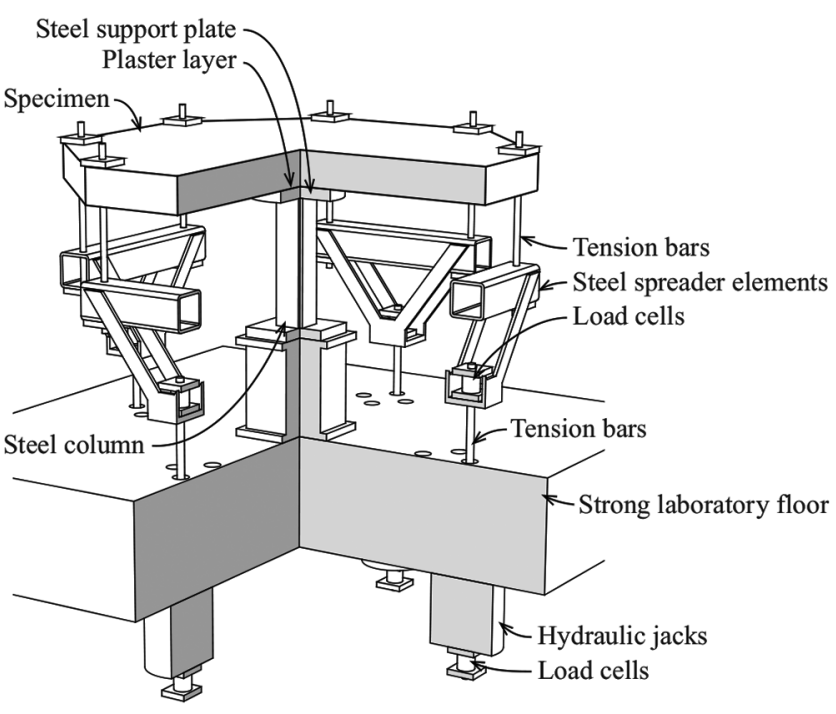

Fig. 9-Test setup.

\section{EXPERIMENTAL CAMPAIGN}

The punching tests were performed in the Structural Concrete Laboratory at École Polytechnique Fédérale de Lausanne (EPFL). In total, 13 slabs were tested. The test series is complemented by two previous punching tests performed in the laboratory with similar parameters (PL7, ${ }^{10}$ $\mathrm{PV}^{24}$ ). The tested specimens (refer to Table 1) are grouped in two series: the first one investigating the influence of column size, while keeping the size of the slab constant, as the second one varies the size of the slab, while keeping the column size constant (Fig. 8(a)). In the first series, the columns were round to avoid the influence of possible stress concentrations in the corners of large columns. ${ }^{8}$ The shapes of the first series' slabs were octagonal to be more comparable to an axisymmetric geometry. In the second series, the columns and the slabs were square.

For applying the load, eight round openings formed by steel tubes were left in the slabs at casting. The centers of these openings were located $120 \mathrm{~mm}$ (4.72 in.) from the slab edge. Thus, the distance $r_{q}$ from the loading points to the center of the column also varied together with the specimen size. The slab thickness, in all cases, was $250 \mathrm{~mm}$ (9.84 in.), representing a typical flat plate in buildings.

All the slabs were cast with normal strength concrete $\left(f_{c}=\right.$ 30.8 to $44.1 \mathrm{MPa}$ [4480 to $6390 \mathrm{psi}$ ]) with mainly limestone alluvial gravel aggregate with maximum size of $16 \mathrm{~mm}$ (0.63 in.). Compressive strength of concrete $f_{c}$ was determined experimentally for each specimen by compression testing concrete cylinders $(150 \times 300 \mathrm{~mm}[6 \times 12$ in.]) cast at the same time and from the same batch of concrete as the test specimens. Concrete tests were performed at 7, 14, and 28 days after casting as well as on the day of the slab test (Table 1) to follow the development of concrete strength.

Tensile (top surface) reinforcement consisted in all the cases of conventional hot-rolled reinforcing steel reinforcing bars that had a clearly defined yielding plateau (ductility class $\mathrm{C}$ of Eurocode $2^{2}$ ). Yield strength of reinforcement $f_{y}$ (Table 1) was determined by tension testing four samples of each diameter bars. The flexural reinforcement was uniformly distributed over the whole slab. The reinforcing bars were placed in four orthogonal layers, two on the bottom and two on the top surface. The top-most and the bottom-most reinforcement layers were oriented in the same direction. This is referred to as the strong axis, whereas the other direction is referred to as the weak axis. Close to the edge of the slab, the top reinforcement was anchored with 180-degree bends. The diameter of top surface reinforcing bars was $16 \mathrm{~mm}$ (0.63 in.) (for four slabs in the first series) or $20 \mathrm{~mm}$ ( $0.79 \mathrm{in}$.) (for four slabs in the first series and for all the second series slabs) and the spacing correspondingly was $125 \mathrm{~mm}$ [4.92 in.] or $100 \mathrm{~mm}$ [3.94 in.], which gives a nominal flexural reinforcement ratio of $0.75 \%$ or $1.5 \%$. The bottom reinforcement consisted of cold-formed $10 \mathrm{~mm}$ (0.39 in.) reinforcing bars with spacing equal to that of the top reinforcement.

In the first series, the shape of the specimens was octagonal (with overall width of $3.00 \mathrm{~m}$ [9.84 ft]), whereas the columns were round (with diameters ranging from $d_{c}=$ $83 \mathrm{~mm}$ [3.27 in.] to $d_{c}=660 \mathrm{~mm}$ [26.0 in.]) (Fig. 8(a)). The reinforcement layout was orthogonal. In the second series, both the slabs and the columns were square. The columns had a side length of $c=260 \mathrm{~mm}$ (10.2 in.) while the side length of the slabs varied from $B=1700 \mathrm{~mm}(5.58 \mathrm{ft})$ to $B=3900 \mathrm{~mm}$ (12.8 ft). Two of the slabs of the second series and a reference slab $\mathrm{PV} 1^{24}$ did not have shear reinforcement, whereas three slabs were equipped with double-headed studs as shear reinforcement (made of ordinary $16 \mathrm{~mm}$ [0.63 in.] ribbed reinforcing steel with yield strength of $f_{y}=560 \mathrm{MPa}[81.2 \mathrm{ksi}]$ and hot-formed heads with diameters equal to three times the diameter of the shaft), fixed on rails in the bottom end to facilitate their installation. The stud rails were placed radially in a star-like pattern (according to the European practice) with 12 studs in each perimeter (Fig. 8(b)). The distance from the edge of the column to the first stud was $s_{0}=80 \mathrm{~mm}$ (3.15 in.) $(0.38 d)$ and the radial distances between subsequent studs $s_{1}=150 \mathrm{~mm}$ (5.91 in.) $(0.71 d)$. The number of stud perimeters was 4,6 , and 8 for slabs PP4, PP5, and PP6, respectively. The amount of shear reinforcement was selected to achieve the highest possible performance of the system that would lead to concrete crushing failure between the column and the first perimeter of studs. ${ }^{3,10,18}$

A view of the test setup is shown in Fig. 9. For all specimens (except for PV1, for which the details can be found elsewhere ${ }^{24}$ ), the load was applied by means of four hydraulic jacks connected to a common oil circuit under a strong $800 \mathrm{~mm}$ (31.5 in.) laboratory floor. The load was spread to eight loading points close to the perimeter of the slab at a distance $r_{q}$ from the slab center. The slab was supported on a central steel column, on which a steel plate representing the column was placed. A thin layer of plaster was placed on the steel plate before placing the specimen to avoid stress concentrations due to possible surface irregularities. The load was applied by manual pumping at a rate of approximately $25 \mathrm{kN} / \mathrm{min}$ (5.6 kip/min).

The applied load was measured with two independent sets of load cells on the hydraulic jacks as well as on the load distribution elements (Fig. 9) and by strain gauges on the steel column. The differences between the results obtained 
with the three measurement systems were negligible. The slab rotation was measured with four digital inclinometers located on the main axes at a distance of $1380 \mathrm{~mm}(4.53 \mathrm{ft})$ from the center of the slab. Vertical displacements of the slab surface were measured with linear variable displacement transducers (LVDTs).

\section{TEST RESULTS}

The main results of the tests are shown in Table 2 and the load-rotation curves in Fig. 10. Slabs without shear reinforcement failed with a sudden drop of load. The rotations at failure varied between 5 and $35 \mathrm{mrad}$, indicating a transition from brittle to a more ductile failure type (it can be noted that slab PV1 had reinforcement with higher yield strength, but no yielding occurred and thus the load-rotation curve is not affected by this issue). At failure, the steel plate simulating the column suddenly penetrated into the slab with a loud noise. Exceptions were the slabs supported on the smallest columns (PE6 and PE10), where the failure was more gradual and accompanied by a quieter cracking sound during few seconds. A diagonal failure crack was revealed after saw-cutting the specimens (Fig. 11). The failure cracks were irregular, with an average angle between the slab surface and the failure crack of approximately 45 degrees or lower in most cases (refer to the photo of a typical crack in Fig. 12(a)). In some specimens, the failure cracks had different shapes and angles on different sides of the column. In addition to the failure crack, several flexural cracks were seen on the saw-cuts that were inclined towards the column.

The slabs with shear reinforcement failed at much larger flexural deformations. In slabs PP5 and PL7, the loadrotation curve reached a short plateau before failing with a sudden decrease of the load, whereas in the case of PP6 (the most slender slab), the testing system did not allow reaching sufficiently large deformations to achieve a punching failure. The cracking patterns on the saw-cuts of all slabs with shear reinforcement showed that the failure zone was severely damaged by flexural and shear cracks as well as by cracks in the anchorage zones of shear studs (Fig. 12(b)). The column plates penetrated also deeper in these slabs. Failure cracks (the cracks with the widest opening after the failure) were located either between the first perimeter of studs and the edge of the column plate or between the first two stud perimeters. The cracks crossing the shear reinforcement had much smaller widths. This suggests that shear reinforcement was not yielding prior to failure which was also indicated by strain gauge measurements close to the top and bottom heads on the studs. Similarly to the slabs without shear reinforcement, the cracking patterns were not symmetric around the columns.

Figure 13 shows the obtained punching shear strengths for Series I (normalized with respect to concrete strength, control perimeter of ACI $318^{1}$ and effective depth) as a function of the column diameter (Fig. 13(a)) and for Series II, as a function of the slab slenderness (Fig. 13(b)). The shear strengths predicted by ACI 318 and CSCT are also plotted (in dashed and in continuous lines, respectively). In the case of round columns, the predicted nominal strength according to ACI 318 is constant up to column diameters of $5.4 d$ (for

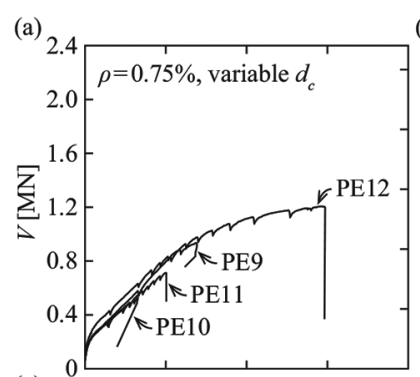

(b)
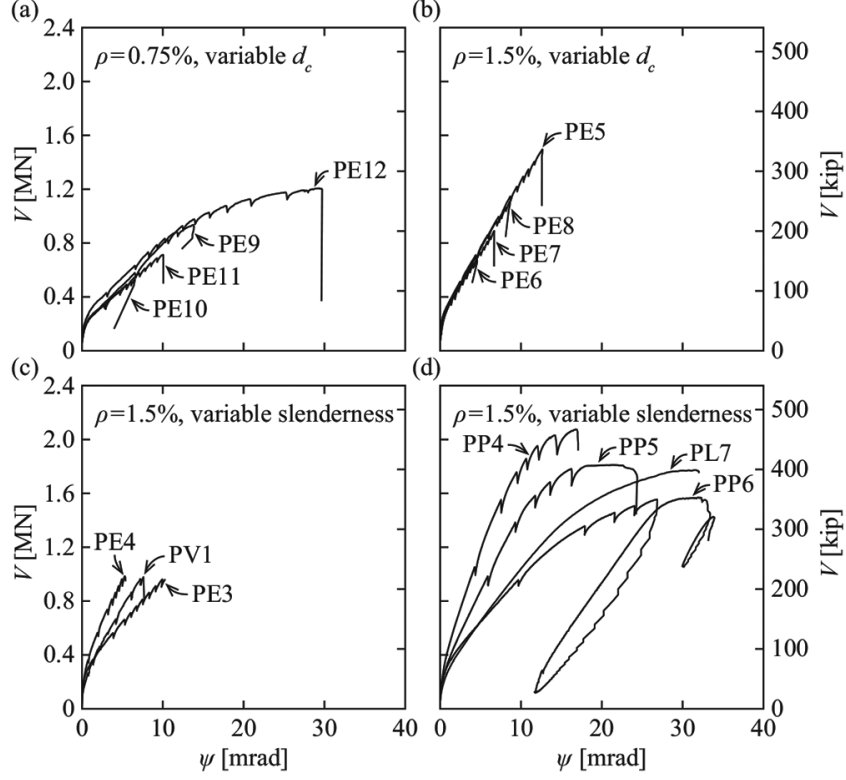

(d)

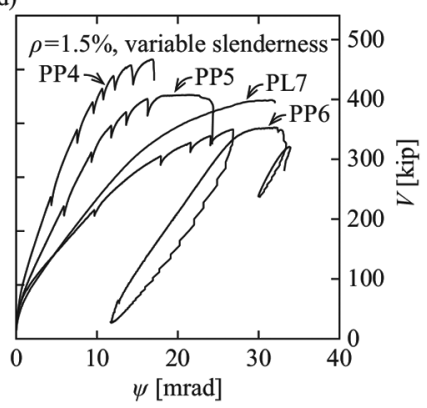

Fig. 10-Load-rotation curves of specimens: (a) slabs with round columns, $\rho_{\text {nom }}=0.75 \%$ and no shear reinforcement, variable column diameter; (b) slabs with round columns, $\rho_{\text {nom }}=1.5 \%$ and no shear reinforcement, variable column diameter; (c) slabs with $\rho_{\mathrm{nom}}=1.5 \%$ and no shear reinforcement, variable specimen size (slenderness); and (d) slabs with $\rho_{\text {nom }}=1.5 \%$ and double-headed shear studs, variable specimen size (slenderness).

square columns, the limit is at $c=4 d$ ). In the experimental results, a decrease of the nominal punching shear strength with increasing column size can already be seen for smaller $d_{c} / d$ ratios. Although the ACI 318 predictions were conservative for all the slabs in the present test campaign, the margin of safety decreased with increasing column sizes and decreasing reinforcement ratios.

Figure 13(b) confirms the $\mathrm{CSCT}^{4}$ prediction that increasing specimen slenderness decreases its punching capacity. Consistently with the predictions of Model Code $2010^{3}$ (Fig. 7), the effect is more pronounced for slabs with shear reinforcement.

All the slabs analyzed in the present research failed below their respective flexural strengths (refer to the calculated $V_{R, \text { test }} / V_{\text {flex }}$ ratios in Table 2 , where the values of $V_{\text {flex }}$ are calculated using yield line method with governing failure mechanism of either a two-way ${ }^{25}$ or a one-way mechanism along the edge of the column with yielding of weak direction reinforcing bars). The $V_{R, \text { test }} / V_{\text {flex }}$ ratios increased with increasing column sizes and slenderness ratios. However, the load-rotation curves in Fig. 10(d) suggest that a limit may have been reached for the specimens with shear reinforcement. These failures may be interpreted as failures due to combined effects of bending and shear. Such combined failures are also possible in continuous slabs in actual structures. However, the flexural strength of an actual slab may be higher than the flexural strength of an isolated test specimen. The CSCT has been extended to predict punching capacities of continuous slabs and can also consider the influence of compressive membrane action in such slabs. ${ }^{20}$ Of the compared models, only the CSCT and the Model Code 2010 
Table 2-Experimental results and predicted punching strengths of test specimens

\begin{tabular}{|c|c|c|c|c|c|c|c|c|c|c|c|c|}
\hline Series & Slab & $d, \mathrm{~mm}$ (in.) & cld & $d_{c} / d$ & $B / 2 d$ & $\psi_{R, \text { test }}, \mathrm{mrad}$ & $V_{R, \text { test }}, \mathrm{kN}$ (kip) & $V_{R, \text { test }} / V_{\text {flex }}$ & $V_{R, \text { test }} / V_{R, A C I}$ & $V_{R, \text { test }} / V_{R, E C 2}$ & $V_{R, \text { test }} / V_{R, C S C T}$ & $V_{R, \text { test }} / V_{R, M C 2010}$ \\
\hline \multirow{16}{*}{ 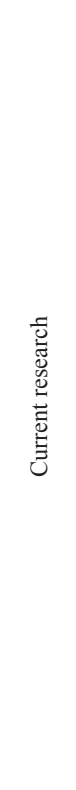 } & PE10 & $210(8.27)$ & - & 0.40 & 7.14 & 6.5 & $530(119)$ & 0.53 & 1.29 & $1.19^{*}$ & 0.92 & 1.12 \\
\hline & PE11 & $215(8.46)$ & - & 0.77 & 6.98 & 10.1 & $712(160)$ & 0.67 & 1.36 & 0.96 & 1.05 & 1.29 \\
\hline & PE9 & $218(8.52)$ & - & 1.51 & 6.88 & 13.8 & $935(210)$ & 0.79 & 1.12 & 1.01 & 1.04 & 1.29 \\
\hline & PE12 & $212(8.35)$ & - & 3.11 & 7.08 & 29.4 & $1206(271)$ & 0.84 & 1.02 & 1.11 & 1.09 & 1.41 \\
\hline & PE6 & $215(8.46)$ & - & 0.39 & 6.98 & 4.5 & $656(148)$ & 0.33 & 1.58 & $1.50^{*}$ & 0.99 & 1.10 \\
\hline & PE7 & $213(8.39)$ & - & 0.78 & 7.04 & 6.7 & 871 (196) & 0.42 & 1.58 & $0.93^{*}$ & 1.07 & 1.21 \\
\hline & PE8 & $214(8.43)$ & - & 1.54 & 7.01 & 8.7 & $1091(245)$ & 0.48 & 1.38 & 0.98 & 1.05 & 1.20 \\
\hline & PE5 & $210(8.27)$ & - & 3.14 & 7.14 & 12.7 & $1476(332)$ & 0.53 & 1.27 & 1.10 & 1.12 & 1.32 \\
\hline & PE4 & $197(7.76)$ & 1.32 & - & 4.31 & 5.3 & $985(222)$ & 0.38 & 1.38 & 1.03 & 0.98 & 1.14 \\
\hline & $\mathrm{PV}^{24}$ & $210(8.27)$ & 1.24 & - & 7.14 & 7.6 & $978(220)$ & 0.35 & 1.33 & 0.99 & 1.07 & 1.22 \\
\hline & PE3 & $204(8.03)$ & 1.27 & - & 9.56 & 10.0 & $961(216)$ & 0.47 & 1.30 & 0.97 & 1.11 & 1.31 \\
\hline & PP4 & $211(8.31)$ & 1.23 & - & 4.03 & 16.8 & 2076 (467) & 0.75 & 1.41 & $1.46^{*}$ & 0.97 & 1.24 \\
\hline & PP5 & $205(8.07)$ & 1.27 & - & 5.61 & 21.5 & $1812(408)$ & 0.85 & 1.27 & $1.29^{*}$ & 1.02 & 1.22 \\
\hline & PP6 & $203(7.99)$ & 1.28 & - & 9.61 & 32.0 & $1569(353)$ & 0.78 & 1.09 & $1.09 *$ & 1.06 & 1.25 \\
\hline & & & & & & & & Mean & 1.31 & 1.12 & 1.04 & 1.24 \\
\hline & & & & & & & & $\mathrm{COV}, \%$ & 12.0 & 15.8 & 5.5 & 6.8 \\
\hline \multirow{7}{*}{ 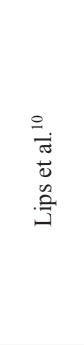 } & PL1 & $193(7.60)$ & 0.67 & - & 7.77 & 5.2 & $682(141)$ & 0.36 & 1.36 & $0.91^{*}$ & 1.03 & 1.16 \\
\hline & PL3 & $197(7.76)$ & 2.64 & - & 7.61 & 11.7 & 1324 (298) & 0.54 & 1.16 & 1.06 & 1.08 & 1.29 \\
\hline & PL6 & $198(7.80)$ & 0.66 & - & 7.58 & 16.6 & $1363(307)$ & 0.71 & 1.30 & $1.77^{*}$ & 1.02 & 1.20 \\
\hline & PL7 & $197(7.76)$ & 1.32 & - & 7.61 & 27.6 & $1773(399)$ & 0.86 & 1.23 & 1.23 & 1.09 & 1.29 \\
\hline & PL8 & $200(7.87)$ & 2.60 & - & 7.50 & - & $2256(508)$ & 0.91 & 0.98 & 1.18 & 1.05 & 1.26 \\
\hline & & & & & & & & Mean & 1.21 & 1.23 & 1.05 & 1.24 \\
\hline & & & & & & & & $\mathrm{COV}, \%$ & 12.2 & 26.5 & 2.9 & 4.7 \\
\hline \multirow{7}{*}{ 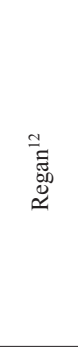 } & $\mathrm{V} / 1$ & $118(4.65)$ & 0.46 & - & 6.78 & - & $170(38)$ & 0.33 & 1.35 & $1.17^{*}$ & 0.81 & 0.98 \\
\hline & $\mathrm{V} / 2$ & $118(4.65)$ & 1.44 & - & 6.78 & - & $280(63)$ & 0.50 & 1.37 & 1.10 & 0.94 & 1.18 \\
\hline & $\mathrm{V} / 3$ & $118(4.65)$ & 0.93 & - & 6.78 & - & $265(60)$ & 0.49 & 1.63 & 1.14 & 1.05 & 1.29 \\
\hline & $\mathrm{V} / 4$ & $118(4.65)$ & 0.86 & - & 6.78 & - & $285(64)$ & 0.53 & 1.35 & 1.15 & 1.02 & 1.26 \\
\hline & $\mathrm{V} / 5$ & $118(4.65)$ & 1.27 & - & 6.78 & - & $285(64)$ & 0.51 & 1.48 & 1.15 & 1.12 & 1.38 \\
\hline & & & & & & & & Mean & 1.44 & 1.14 & $0.99^{\dagger}$ & $1.22^{\dagger}$ \\
\hline & & & & & & & & $\mathrm{COV}, \%$ & 8.5 & 2.2 & 12.1 & 12.5 \\
\hline \multirow{12}{*}{ 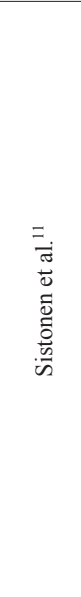 } & L1 & $172(6.77)$ & - & 1.17 & 5.15 & - & $503(113)$ & 0.75 & 1.44 & 1.26 & 1.08 & 1.46 \\
\hline & L2 & $176(6.93)$ & - & 1.15 & 5.03 & - & $537(121)$ & 0.78 & 1.49 & 1.30 & 1.12 & 1.52 \\
\hline & L3 & $173(6.81)$ & - & 1.16 & 5.12 & - & $530(119)$ & 0.79 & 1.51 & 1.32 & 1.13 & 1.53 \\
\hline & L4 & $170(6.69)$ & - & 2.36 & 5.79 & - & $686(154)$ & 0.66 & 1.30 & 1.26 & 1.05 & 1.42 \\
\hline & L5 & $172(6.77)$ & - & 2.32 & 5.73 & - & $696(157)$ & 0.66 & 1.31 & 1.26 & 1.05 & 1.42 \\
\hline & L6 & $175(6.89)$ & - & 2.32 & 5.63 & - & $799(180)$ & 0.74 & 1.45 & 1.41 & 1.18 & 1.59 \\
\hline & L7 & $177(6.97)$ & - & 1.14 & 5.56 & - & $478(108)$ & 0.53 & 1.53 & 1.13 & 1.05 & 1.34 \\
\hline & L8 & $174(6.85)$ & - & 5.17 & 7.10 & - & $1111(250)$ & 0.50 & 1.28 & 1.25 & 1.11 & 1.51 \\
\hline & L9 & $172(6.77)$ & - & 5.22 & 7.18 & - & 1107 (249) & 0.50 & 1.29 & 1.26 & 1.12 & 1.53 \\
\hline & L10 & $173(6.81)$ & - & 5.21 & 7.14 & - & 1079 (243) & 0.48 & 1.25 & 1.22 & 1.08 & 1.48 \\
\hline & & & & & & & & Mean & 1.39 & 1.27 & 1.10 & 1.48 \\
\hline & & & & & & & & $\mathrm{COV}, \%$ & 7.9 & 5.7 & 3.7 & 4.9 \\
\hline \multicolumn{9}{|c|}{ All tests, mean } & 1.34 & 1.18 & 1.05 & 1.30 \\
\hline \multicolumn{9}{|c|}{ All tests, COV, \% } & 11.3 & 15.2 & 6.7 & 11.2 \\
\hline
\end{tabular}

$v_{R, \max }$ governs Eurocode 2 prediction.

${ }^{\dagger} d_{g}$ is not reported for these experiments; $d_{g}=16 \mathrm{~mm}$ ( $0.63 \mathrm{in}$.) is assumed (assuming $d_{g}=10 \mathrm{~mm}$ [0.39 in.] would give a mean of 1.04 and 1.28 for CSCT and Model Code 2010 , respectively; assuming $d_{g}=20 \mathrm{~mm}$ [0.79 in.] would give 0.96 and 1.18 ). 

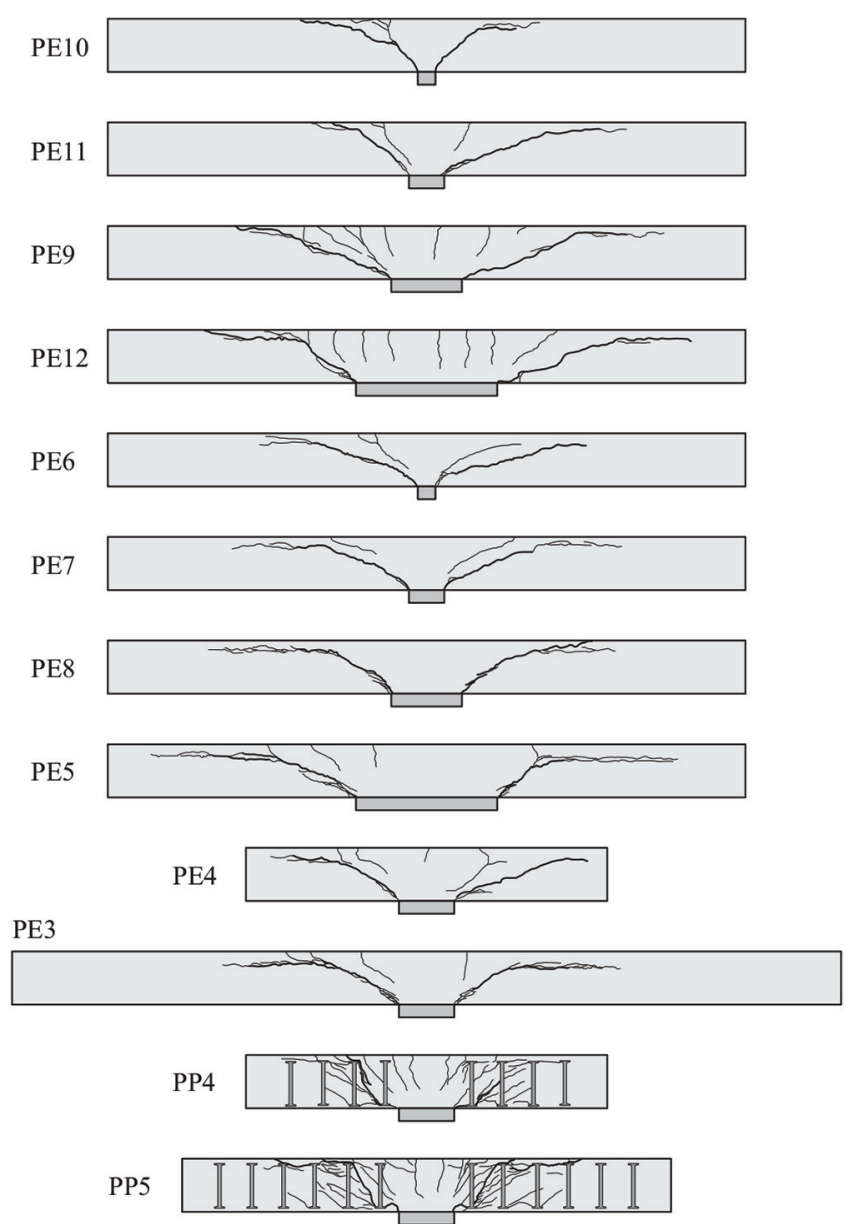

PP6

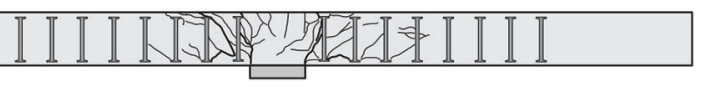

Fig. 11-Saw-cuts of slabs along weak axis.

provide a physical method for assessing and comparing the behavior of both continuous and isolated slabs.

\section{COMPARISON OF TEST RESULTS TO CODE PREDICTIONS}

Figure 14 compares the results of the present test campaign to the predictions of ACI 318, ${ }^{1}$ Eurocode $2,{ }^{2} \mathrm{CSCT},{ }^{4}$ and Model Code $2010^{3}$ (Level of Approximation II). The details about the formulas used in the calculations can be found in Appendix $\mathrm{A}^{*}$ of this paper. Previous results of similar campaigns by Lips et al. ${ }^{10}$ with variable column sizes, Regan ${ }^{12}$ with very small columns, and Sistonen et al. ${ }^{11}$ with variable slab slenderness and column size-slab depth ratios are also included. The comparisons are shown as a function of $c / d$ or $d_{c} / d$ and specimen slenderness ratio $(B / 2 d)$. The values are also given in Table 2.

The design formula of ACI 318 yields conservative predictions (the average measured-to-predicted strength of all the experiments is 1.34). However, the predictions are less conservative for larger column sizes in combination with lower reinforcement ratios and round columns (the

\footnotetext{
*The Appendix is available at www.concrete.org/publications in PDF format, appended to the online version of the published paper. It is also available in hard copy from ACI headquarters for a fee equal to the cost of reproduction plus handling at the time of the request.
}

(a)

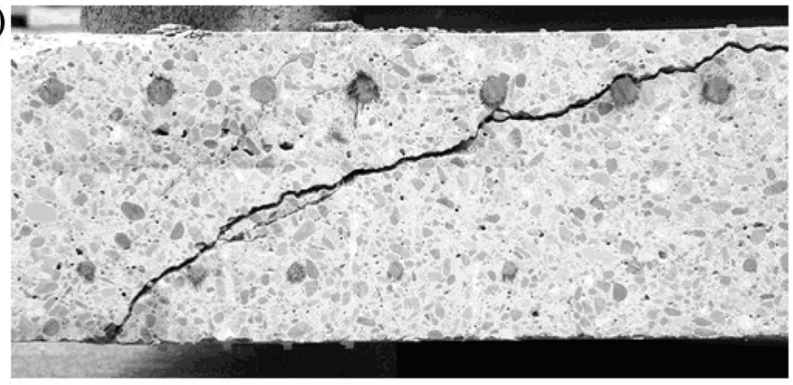

(b)

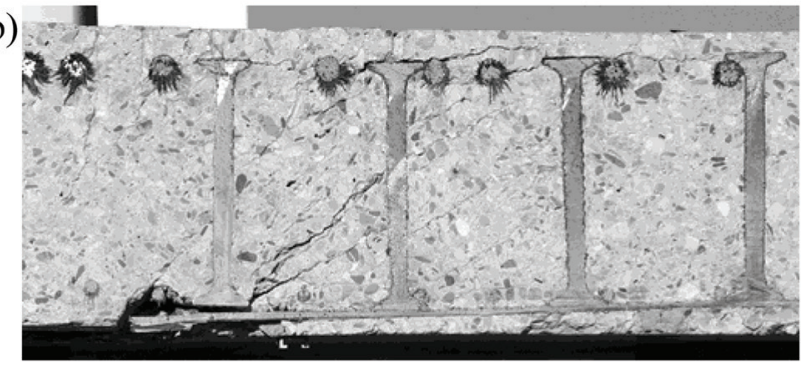

Fig. 12-Photos of typical punching cracks on saw-cut: (a) slab without shear reinforcement (PE7); and (b) slab with shear reinforcement (PP4).

(a)

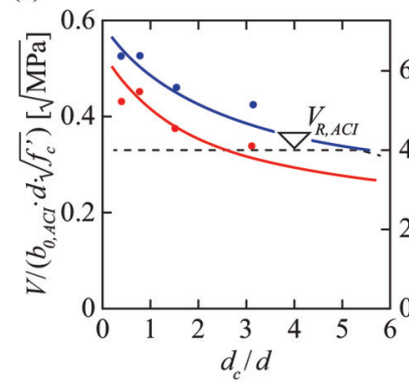

(b)

$\begin{aligned} \rho & =0.75 \% \text {, without shear reinforcement } \\ \rho & =1.50 \% \text {, without shear reinforcement } \\ \rho & =1.50 \% \text {, with shear reinforcement }\end{aligned}$

Fig. 13-Normalized nominal shear stresses at failure on ACI 318 control perimeter and comparison to CSCT (continuous lines) and ACI 318 (dashed lines) predictions: (a) depending on column diameter (Series I); and (b) depending on specimen slenderness (Series II).

lowest ratio of experimental load to prediction in current campaign is 1.02 for slab PE12). The slenderness effect is also neglected and thus a reduction in the margin of safety can be seen for higher slenderness ratios. The coefficient of variation $(\mathrm{COV})$ for all the tests is $11.3 \%$.

The predictions of Eurocode 2 for the tests of the present test campaign fit the test results well if the governing verification is the one performed at the basic control perimeter located at $2 d$ from the column edge. However, when the governing failure mode is exceeding $v_{R, \max }$ at the column edge, the results show larger scatter. This limit also governs the three slabs with shear reinforcement tested in the current campaign, as it assumes the same strength for both slabs with and without shear reinforcement. This lack of agreement has also been presented in previous studies, ${ }^{10}$ showing a clear increase of punching capacity as a result of using shear reinforcement even in the case of small columns (with respect to 

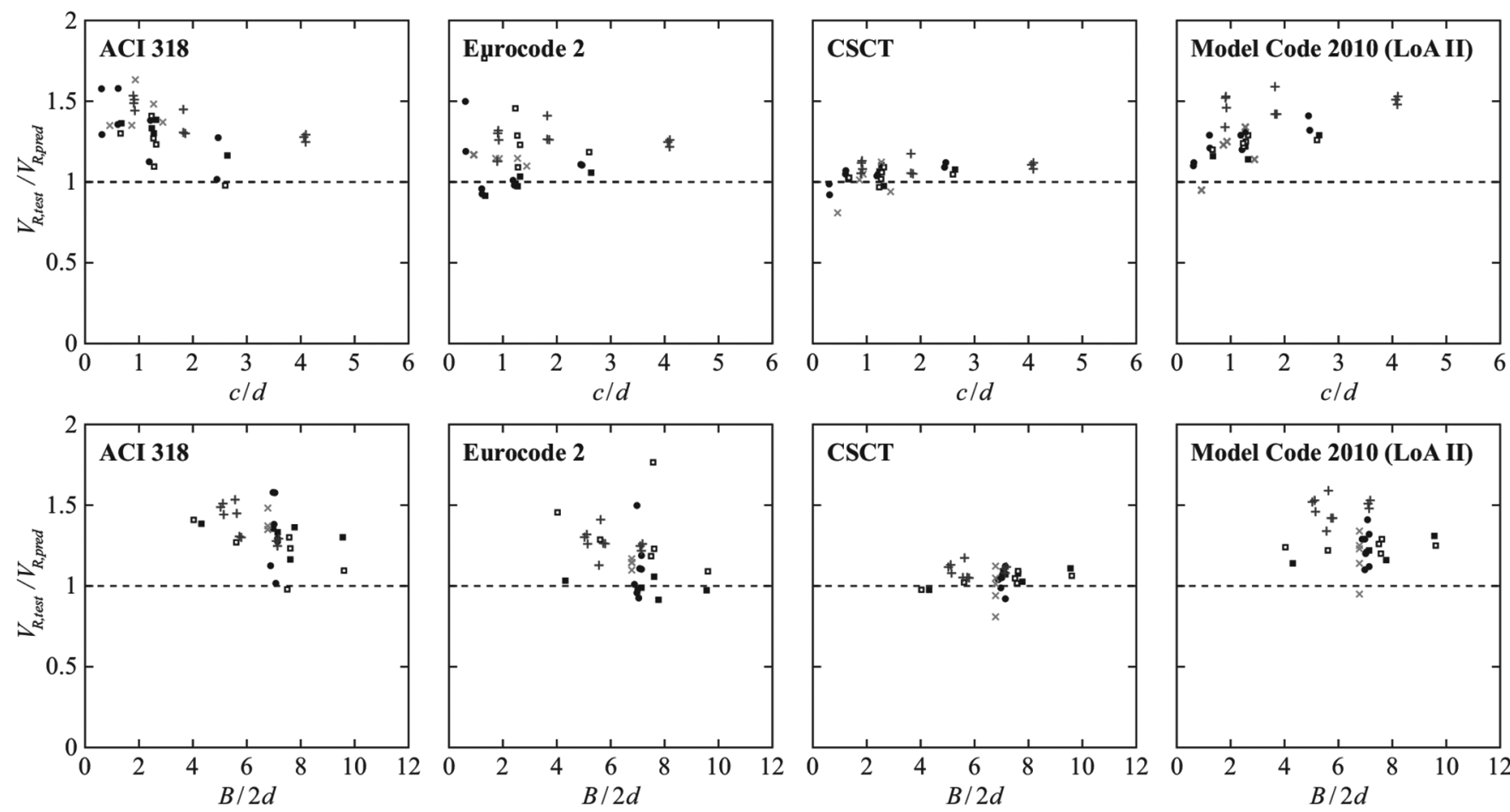

- round columns a with shear reinforcement

+ tests by Sistonen et Al. ${ }^{11}$

- square columns $\quad \times$ tests by Regan ${ }^{12}$

Fig. 14-Comparison of test results to codes of practice (for round columns, $\mathrm{c}=\pi / 4 \cdot \mathrm{d}_{\mathrm{c}}$ ).

slab depth). Thus, these predictions of Eurocode 2 are fairly conservative for these cases. On the contrary, Eurocode 2 gives excellent predictions for the five tests of Regan ${ }^{12}$ with $c / d$ ratios between 0.46 and 1.44 where $v_{R, \max }$ is governing in only one case. These inconsistencies show that the Eurocode 2 verification of punching of small columns may not capture the actual influencing parameters correctly. For all the results, the average measured-to-predicted strength is 1.18 with a COV of $15.2 \%$.

Regarding the predictions of both ACI 318 and Eurocode 2 for slabs with shear reinforcement (plotted with square markers with white fill in Fig. 14), a trend can be observed that leads to less conservative predictions for increasingly slender slabs. This is caused by the fact that although Eurocode 2 punching provisions account for the flexural reinforcement ratio, neither of the codes take the influence of slab slenderness into account.

The CSCT provides consistent results for all column size and specimen slenderness ratios. The mean ratio of experimental to predicted strength is 1.05 and the coefficient of variation $6.7 \%$. For the smallest columns (PE6 and PE10 with $d_{c}=83 \mathrm{~mm}[3.27 \mathrm{in}$.$] and \mathrm{V} / 1$ of Regan ${ }^{12}$ with $d_{c}=54 \mathrm{~mm}$ [2.13 in.]), an overestimate of the punching strength can be seen. In these cases, the compressive stresses at failure under the column were close to $3 f_{c}$ (in other specimens, the average stress under the column plate always remained below $f_{c}$ ) and a different failure mode than typical to punching may have been attained in these tests. This hypothesis is also supported by observations during tests of the present experimental campaign and saw-cut patterns that showed a more gradual failure with crushing-like noise and steeper failure cracks.
The punching provisions of Model Code 2010 are based on the CSCT and the predictions are therefore similar. The differences can be explained by the different level of safety (the failure criterion curve of Model Code 2010 has been calibrated so that $5 \%$ of the experimental results are below the predicted strength, whereas the CSCT failure criterion corresponds to a mean of test results) and the fact that the nonlinear load-rotation curve is replaced with a simplified parabolic relationship in Model Code 2010. ${ }^{3}$ The mean of the predictions is 1.30 and COV $11.2 \%$. The influence of the two investigated parameters (column size with respect to slab depth and slab slenderness) is yet suitably reproduced.

\section{SUMMARY AND CONCLUSIONS}

In this paper, the results of an experimental campaign investigating the influence of specimen slenderness, column size, and flexural reinforcement ratio on the shear strength of interior slab-column connections are presented. The results are compared to the predictions of ACI 318, Eurocode 2, the CSCT, and Model Code 2010.

The main conclusions are:

1. Experiments show that slenderness of a specimen influences the stiffness of its load-rotation response. Through influencing the crack widths, it also affects the punching strength. This effect is especially significant in the slabs with shear reinforcement and has to be considered when selecting the specimen size in the design of punching tests.

2. Contrary to the experimental evidence, this parameter is not considered in the Eurocode 2 and ACI 318 punching provisions.

3. Punching tests on slabs with varying support sizes indicate that the unitary nominal shear strength on a control 
perimeter at $d / 2$ from the column face decreases with increasing column size. This effect can also be explained by the influence of cracking developing in the vicinity of the supported area.

4. The decrease of the unitary nominal shear strength in ACI 318 for large columns may lead to an overestimate of the punching strength in the case of lower reinforcement ratios and thicker slabs. However, if the perimeter is located at $2 d$ as in Eurocode 2, the punching strength of very small columns is overestimated. The deformation-dependent nominal shear stress of CSCT describes the punching phenomenon in a physical manner and provides good estimates for all different column sizes studied.

5. The verification in Eurocode 2 that limits the shear stress at a control perimeter located at the column face neglects the influence of several important parameters and therefore may lead to very conservative results in the case of slabs with shear reinforcement.

6. The CSCT and the punching provisions of Model Code 2010 consistently account for the influences of column size and slab slenderness. The CSCT provides the best mean and coefficient of variation for the ratio of experimental to predicted punching load amongst the compared models.

\section{AUTHOR BIOS}

Jürgen Einpaul is a Research Assistant and PhD Candidate at the School of Architecture, Civil, and Environmental Engineering (ENAC) of École Polytechnique Fédérale de Lausanne (EPFL), Lausanne, Switzerland. He received his MS from Tallinn University of Technology, Tallinn, Estonia, in 2010. His research interests include the mechanics of punching shear failure of reinforced concrete slabs and the behavior of continuous slabs.

Jan Bujnak is a Research and Development Manager at Peikko Group Corporation, Lahti, Finland. He received his PhD from Polytech Clermont-Ferrand, Aubière, France, in 2007. His research interests include bond, fastening technology, and punching shear in flat slabs.

Miguel Fernández Ruiz is a Senior Lecturer and Scientist at EPFL-ENAC. He was the co-recipient of the ACI Wason Medal for the Most Meritorious Paper in 2014. His research interests include the serviceability behavior of structures, bond, shear and punching shear, and the modeling of structural concrete using stress fields.

ACI member Aurelio Muttoni is a Professor and Head of the Structural Concrete Laboratory at EPFL-ENAC. He was the recipient of the ACI Chester Paul Siess Award for Excellence in Structural Research in 2010 and co-recipient of the ACI Wason Medal for the Most Meritorious Paper in 2014. His research interests include the theoretical bases of the design of reinforced concrete structures, shear and punching shear, fiber-reinforced high-strength concrete, soil-structure interaction, and the conceptual design of bridges.

\section{ACKNOWLEDGMENTS}

The work presented in this paper was funded in part by the Swiss National Science Foundation (Project No. 200021 137658). Part of the test campaign was financed by Peikko Group. The authors would like express their sincere gratitude for the support.

\section{REFERENCES}

1. ACI Committee 318, "Building Code Requirements for Structural Concrete (ACI 318-14) and Commentary (ACI 318R-14)," American Concrete Institute, Farmington Hills, MI, 2014, 519 pp.
2. EN 1992-1-1:2004, "Design of Concrete Structures—Part 1: General Rules and Rules for Buildings," European Committee for Standardization (CEN), Brussels, Belgium, 2004, 225 pp.

3. Fédération internationale du béton, " $f i b$ Model Code for Concrete Structures 2010," Ernst \& Sohn, Berlin, Germany, 2013, 434 pp.

4. Muttoni, A., "Punching Shear Strength of Reinforced Concrete Slabs without Transverse Reinforcement," ACI Structural Journal, V. 105, No. 4, July-Aug. 2008, pp. 440-450.

5. Muttoni, A.; Ruiz, M. F.; Bentz, E. C.; Foster, S. J.; and Sigrist, V., "Background to the Model Code 2010 Shear Provisions-Part II Punching Shear," Structural Concrete, V. 14, No. 3, 2013, pp. 204-214. doi: 10.1002/ suco. 201200064

6. Kinnunen, S., and Nylander, H., "Punching of Concrete Slabs without Shear Reinforcement," Transactions of the Royal Institute of Technology, No. $158,1960,112$ pp.

7. Vanderbilt, M. D., "Shear Strength of Continuous Plates," Journal of the Structural Division, ASCE, V. 98, 1972, pp. 961-973.

8. Sagaseta, J.; Tassinari, L.; Fernández Ruiz, M.; and Muttoni, A., "Punching of Flat Slabs Supported on Rectangular Columns," Engineering Structures, V. 77, 2014, pp. 17-33. doi: 10.1016/j.engstruct.2014.07.007

9. Vaz Rodrigues, R.; Fernández Ruiz, M.; and Muttoni, A., "Shear Strength of R/C Bridge Cantilever Slabs," Engineering Structures, V. 30, No. 11, 2008, pp. 3024-3033. doi: 10.1016/j.engstruct.2008.04.017

10. Lips, S.; Fernández Ruiz, M.; and Muttoni, A., "Experimental Investigation on Punching Strength and Deformation Capacity of ShearReinforced Slabs," ACI Structural Journal, V. 109, No. 6, Nov.-Dec. 2012, pp. 889-900.

11. Sistonen, E.; Lydman, M.; and Huovinen, S., "The Geometrical Model of the Calculation Formula of the Punching Shear Capacity of the Reinforced Concrete Slab," Report No. 69, Helsinki University of Technology, Espoo, Finland, 1997, 95 pp. (in Finnish)

12. Regan, P. E., "Symmetric Punching of Reinforced Concrete Slabs," Magazine of Concrete Research, V. 38, No. 136, 1986, pp. 115-128. doi: 10.1680/macr.1986.38.136.115

13. Moe, J., "Shearing Strength of Reinforced Concrete Slabs and Footings under Concentrated Loads," Bulletin D47, Portland Cement Association, Skokie, IL, 1961, 135 pp.

14. ASCE-ACI Task Committee 426 on Shear and Diagonal Tension, "The Shear Strength of Reinforced Concrete Members-Slabs," Journal of the Structural Division, ASCE, V. 100, 1974, pp. 1543-1591.

15. Comité Euro-International du Béton, "CEB-FIP Model Code 1990," Thomas Telford, London, UK, 1993, $460 \mathrm{pp}$.

16. BS 8110, "Structural Use of Concrete," British Standards Institution, London, UK, 1985, $124 \mathrm{pp}$.

17. Fernández Ruiz, M.; Muttoni, A.; and Sagaseta, J., "Shear Strength of Concrete Members without Transverse Rinforcement: A Mechanical Approach to Consistently Account for Size and Strain Effects," Engineering Structures, V. 99, 2015, pp. 360-372. doi: 10.1016/j.engstruct.2015.05.007

18. Fernández Ruiz, M., and Muttoni, A., "Applications of Critical Shear Crack Theory to Punching of Reinforced Concrete Slabs with Transverse Reinforcement," ACI Structural Journal, V. 106, No. 4, July-Aug. 2009, pp. 485-494

19. EN 1992-1-1/A1:2014, "Amendment for: Design of Concrete Structures-Part 1: General Rules and Rules for Buildings," European Committee for Standardization (CEN), Brussels, Belgium, 2014, 4 pp.

20. Einpaul, J.; Fernández Ruiz, M.; and Muttoni, A., "Influence of Moment Redistribution and Compressive Membrane Action on Punching Strength of Flat Slabs," Engineering Structures, V. 86, 2015, pp. 43-57. doi: 10.1016/j.engstruct.2014.12.032

21. Staller, M., "Empirical Model by Staller," fib Bulletin 12: Punching of structural concrete slabs, Fédération internationale du béton, Lausanne, Switzerland, 2001, pp. 56-61.

22. Nylander, H., and Kinnunen, S., "Dimensionering Med Hänsyn till Genomstansning vid Koncentrerat Stöd," Betonghandboken-Konstruktion, Second Edition, AB Svensk Byggtjänst, Stockholm, Sweden, 1990, pp. 648-675.

23. SIA 262:2003, "Concrete Structures," Swiss Society of Engineers and Architects, Zürich, Switzerland, 2003, 94 pp.

24. Fernández Ruiz, M.; Muttoni, A.; and Kunz, J., "Strengthening of Flat Slabs against Punching Shear Using Post-Installed Shear Reinforcement," ACI Structural Journal, V. 107, No. 4, July-Aug. 2010, pp. 434-442.

25. Guandalini, S.; Burdet, O.; and Muttoni, A., "Punching Tests of Slabs with Low Reinforcement Ratios," ACI Structural Journal, V. 106, No. 1, Jan.-Feb. 2009, pp. 87-95. 
